NOTA CIENTÍFICA

\title{
La cola de caballo (Equisetum, Equisetaceae) comercializada y exportada del Perú
}

\author{
Horsetail (Equisetum, Equisetaceae) in commerce and exported from Peru
}

\section{Blanca León}

Museo de Historia Natural, Universidad Nacional Mayor de San Marcos, Av. Arenales 1256, Jesús María, Lima. Aptdo. 14-0434, Lima14, Perú

leon@austin.utexas.edu

Presentado: $\quad$ 07/09/2012

$20 / 11 / 2012$

Publicado online: 15/01/2013

\begin{abstract}
Resumen
Varios productos derivados de plantas se exportan del Perú como suplementos nutricionales, condimentos y otros usos, entre estos últimos tipos se encuentra el helecho "cola de caballo". Tres nombres se emplean en el comercio: Equisetum arvense, E. bogotense y "E. hiemale", los cuales no corresponden a las plantas exportadas, las que en cambio son E. giganteum, una especie reconocible por detalles morfológicos en sus ejes, ornamentación y distribución de sus estomas.
\end{abstract}

Palabras claves: Equisetum; helecho; identificación; cola de caballo; Perú.

\section{Abstract}

Several plant products are exported from Peru as food supplements (nutraceuticals), condiments and other uses for human consumption, among them the horsetail fern. Three names are used in commerce: Equisetum arvense, E. bogotense and "E. hiemale"; none of which represent the species being exported; instead the species in commerce is $E$. giganteum, easily recognizable by morphological details of their axes, ornamentation and stomata distribution.

Keywords: Equisetum; fern identification; horsetail; Peru.
El incremento en la demanda de los mercados por plantas y productos derivados de ellas aumenta simultáneamente el riesgo de la identificación errada. Esta situación describe el caso de la "cola de caballo", la cual es exportada a diversos mercados en países vecinos, Europa y los Estados Unidos de N.A. La exportación de esta planta alcanzó los últimos tres años 2320, 9680 y 21820 kg/año (Ministerio de Agricultura, 2009, 2010, 2011). Los registros oficiales emplean el nombre común y citan como lugar de producción para los dos últimos años solamente al departamento de Lima, situación que no refleja las fuentes de exportaciones existentes en el Perú y disponibles a través del acceso en línea. La "cola de caballo" es ofertada en paquetes que permiten observar el contenido (Figs. 1 A-B) y estos incluyen numerosos ejes $>3 \mathrm{~mm}$ usualmente estériles. Los paquetes que se venden en los EE.UU. de N.A. (Fig. 1A) llevan el nombre de "Equisetum bogotense", mientras que los paquetes que se ofertan en el mercado peruano (Fig. 1B) y la oferta en línea de los exportadores llevan ya sea el nombre de "Equisetum arvense" o el de "Equisetum hiemale".

Esta nota tiene por tanto como objetivos aclarar la identificación botánica de las colas de caballo comercializadas industrialmente en el Perú y proveer de ayuda visual para su reconocimiento.

Equisetum es un género de helechos llamados comúnmente "colas de caballo" de distribución mundial y de mayor riqueza en el hemisferio norte. Este género es reconocible por los ejes longitudinalmente surcados con costillas, por lo general, pronunciadas, con hojas verticiladas reducidas a escamas que forman una vaina y por esporofilos agrupados distalmente en unas estructuras a manera de cono, los estróbilos. En el Perú se reconoce en la actualidad tres especies: E. bogotense Kunth, E. giganteum L. y la escasamente reportada E. myriochaetum Schltdl. \& Cham. Existe la posibilidad que ocurran también híbridos
(Equisetum X schaffneri Milde) entre estas dos últimas en las áreas de contacto como sí ocurre en América Central (Hauke 1969; Mickel \& Smith 2004). Las tres especies se hallan distribuidas en casi toda la América tropical, y en el Perú las dos primeras crecen en casi todos los departamentos, ocupando ambientes húmedos y alterados desde el nivel del mar hasta los $4200 \mathrm{~m}$ de altitud.

El uso de Equisetum como planta diurética es conocido en varios países de la región andina, especialmente $E$. bogotense y $E$. giganteum (Navarrete et al. 2006). La presencia de oleorresinas en esa última es tema de interés farmacológico (e.g. Michielin et al. 2005; Danielski et al. 2007) habiéndose evaluado su caracterización fisicoquímica para control de calidad (Francescato et al. 2011).

La distinción morfológica de las especies peruanas se basa inicialmente en las dimensiones y ramificación de las plantas. Equisetum bogotense alcanza $<50 \mathrm{~cm}$ de largo, ejes $<2 \mathrm{~mm}$ de

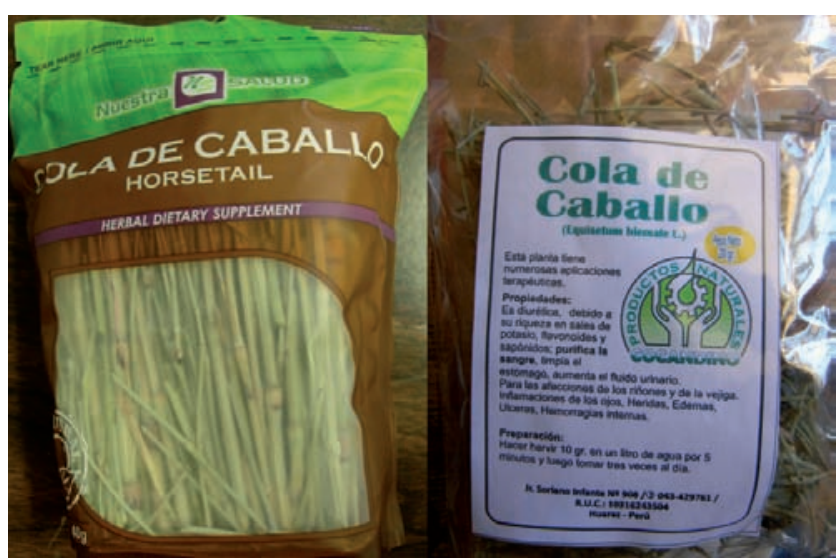

Figura 1. Paquetes de "cola de caballo" de producción industrial. A la izquierda bolsa ofertada en los Estados Unidos de N.A., a la derecha en la ciudad de Huaraz. 


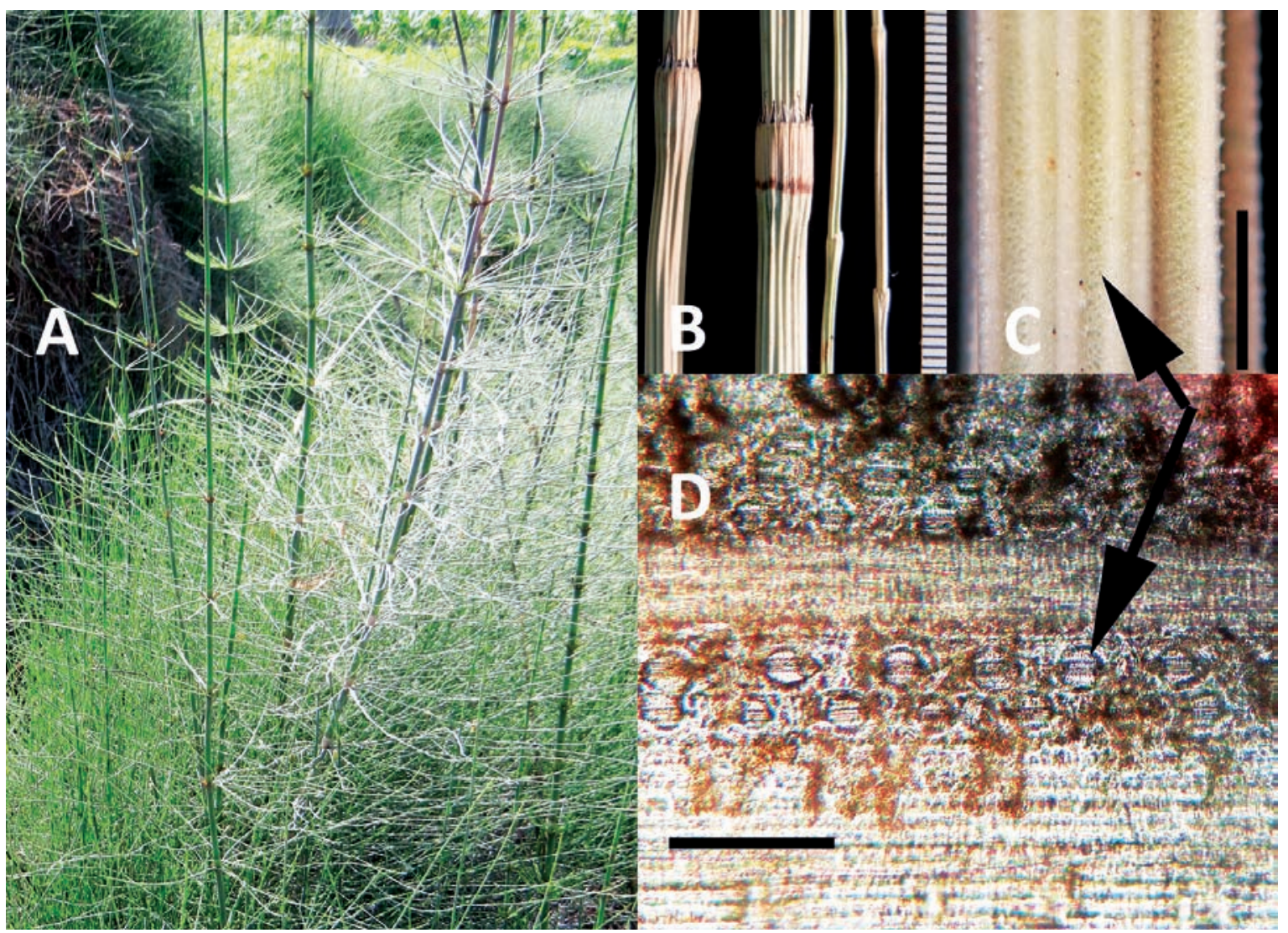

Figura 2. Equisetum giganteum L. y detalles morfológicos para su identificación. A. Hábito, planta de 1,2 m de alto, cuenca del río Mala (León \& Young 4862 USM), B. Ramas de E. giganteum en venta en los EEUU de N.A., C. Detalle a 2X de rama, la barra vertical equivale a 3,5 mm, D. Vista microscópica de las dos hileras de estomas, la barra horizontal equivale a 0,3 mm

ancho, con 4-7 surcos longitudinales y ramas de número menor que los surcos (1 - 4); mientras que las especies E. giganteum (Fig. 2A) y E. myriochaetum del subgénero Hippochaete superan $1 \mathrm{~m}$ de alto, ejes $>3 \mathrm{~mm}$ de ancho, con $16-25$ surcos y ramas, por lo general, de igual número que los surcos rodeando a los ejes. Estas dos últimas especies se pueden diferenciar con una lupa (de 10 X) por el número de hileras de estomas y el margen de las costillas, siendo para $E$. giganteum de $2-6$ hileras y costillas dentadas, en cambio E. myriochaetum tiene estomas en una hilera y costillas aserradas. El material examinado (Figs. 2 B-D) presenta ejes de $2-4 \mathrm{~mm}$ ancho, ramas de igual número que los surcos, estomas en $2-3$ hileras y costillas de margen dentado, lo que permite reconocerlo como Equisetum giganteum L. Pero, dada la posibilidad de una confusión con $E$. myriochaetum se sugiere una verificación constante y un examen de las condiciones de sus poblaciones.

La "cola de caballo" en comercio, Equisetum giganteum L., es considerada como planta de uso tradicional y no terapéutico por ello su aprovechamiento y registro de exportación se enmarca en la ley 27821 (Ley de Promoción de Complementos Nutricionales para el Desarrollo Alternativo). Sin embargo, con esta ley y su futura reglamentación se promueven actividades productivas, pero no garantizan la identificación correcta a lo largo de toda la cadena productiva que priorice la calidad y el buen manejo de los recursos, especialmente para plantas como Equisetum cuya extracción proviene de poblaciones silvestres.

\section{Agradecimientos}

Agradezco a Lucila Bocángel de León, Efraín León Bocángel, Mónica Arakaki, Flor Henderson y Kenneth Young por el apoyo en la obtención de Equisetum en el Perú y los EE.UU. de N.A.

\section{Literatura citada}

Danielski, L., E. M. Z. Michielin \& S. R. S. Ferreira. 2007. Horsetail (Equisetum giganteum L.) oleoresin and supercritical CO2: Experimental solubility and empirical data correlation. J. Food Engineer. 78:1054-1059.

Francescato, L. N., D. A. Quinteros, S. Bordignon, V. L. Bassani \& A. T. Henriques. 2011. Physicochemical characterization for quality control of Equisetum giganteum L. Latin Amer. J. Pharm. 30:1196-1201.

Hauke, R. L. 1969. The natural history of Equisetum in Costa Rica. Revista Biol. Trop. 15:269-281.

Michielin, E. M. Z., L. F. V. Bresciani, L. Danielski, R. A. Yunes \& S. R. S. Ferreira. 2005. Composition profile of horsetail (Equisetum giganteum L.) oleoresin: comparing SFE and organic solvents extraction. J. Supercrit. Fluids 33:131-138.

Mickel, J. T. \& A. R. Smith. 2004. The Pteridophytes of Mexico. Mem. New York Bot. Gard. 88:317-320.

Ministerio de Agricultura. 2009. Perú Forestal en Números. Año 2008. Dirección General de Forestal y Fauna. Pp. 1-88.

Ministerio de Agricultura. 2011. Perú Forestal en Números. Año 2010. Dirección General de Forestal y Fauna. P p . $1-87$.

Navarrete, H., B. León, J. Gonzales, D. K. Avilés, J. Salazar-Lecaro, F. Mellado, J. Albán \& B. Øllgaard. 2006. Helechos. Pp. 385-411. En: M. Moraes R., B. Øllgaard, L. P. Kvist, F. Borschenius \& H. Balslev, eds. Botánica económica de los Andes centrales. Universidad Nacional de San Andrés, La Paz, Bolivia. Pp. 385-411. 